\title{
Modelling of debris bed reflooding in PEARL experimental facility with MC3D code
}

Janez Kokalj, ${ }^{\mathrm{a}, \mathrm{b}}$, Mitja Uršiča ${ }^{\mathrm{a}}$, Matjaž Leskovar ${ }^{\mathrm{a}}$, Libuse Piar ${ }^{\mathrm{c}}$, Renaud Meignen ${ }^{\mathrm{c}}$

a Jožef Stefan Institute, Jamova cesta 39, SI-1000 Ljubljana, Slovenia

${ }^{\mathrm{b}}$ University of Ljubljana, Kongresni trg 12, SI-1000 Ljubljana, Slovenia

' IRSN (French Nuclear Safety Institute), Cadarache Nuclear Center, BP 3, 13115 Saint-Paul-lez-Durance, France

Corresponding author: Janez Kokalj

Jožef Stefan Institute, Jamova cesta 39, SI-1000 Ljubljana, Slovenia janez.kokalj@ijs.si

Tel.: +38615885348

\section{Highlights}

- MC3D simulations of PEARL experiments are presented.

- The general trends of the flows are recovered and explained.

- The 2-D behaviour, with faster progression in the bypass, is highlighted and explained.

- The impact of porosity in the 2-D reflooding configurations is presented.

\section{Keywords}

nuclear safety, severe accident, debris bed coolability, debris bed reflooding

\section{Abstract}

A hypothetical severe accident in a nuclear power plant has the potential for causing severe core damage, including a meltdown. To prevent or in the case of an already formed debris bed to limit the in-vessel core degradation, the basic severe accident management strategies consider the in-vessel reflooding to ensure the debris bed coolability.

The purpose of our research was to understand the key processes and conditions related to the in-vessel debris bed coolability in the bottom reflooding conditions. Recently, experimental tests in the PEARL facility (IRSN, France) were performed to highlight the behaviour of the steam and water flow in a hot porous medium and to provide experimental data to validate 2-D and 3-D models for the debris bed reflooding. Our aim was to analyse chosen PEARL 
experiments performed at the atmospheric pressure. The objective was to analyse the importance of the uncertainties in the initial and boundary conditions on the simulation results and to assess the heat transfer modelling approaches. Simulations were performed using the MC3D code (IRSN, France).

In general, the performed simulations are in good agreement with the experiments. The general features, in particular the water preferential entrainment in the bypass are recovered and the analysis of calculation gives further information on the mechanisms. In particular, the mechanism of water deviation in the bypass (2-D behaviour) is described. The hypothesis of water dragged by steam coming from the debris bed region cannot be supported. However, the simulation results are indicating a noticeable impact of the actual conditions as the water temperature and the initial support bed and bypass temperature. The simulations, varying the porosity of the test section, showed that this impact affects the flow configuration and is important for cases with the 2-D configuration. The reflooding capabilities in this configuration may depend strongly on the characteristics of the debris bed. Changes in the heat transfer modelling do not have greater effect on the simulation results.

\section{Introduction}

During a hypothetical severe accident in a nuclear power plant a reactor core degradation might occur. A debris bed may be formed as a consequence of the core deformation or when the already melted core drops into the water (Magallon, 2006). Severe accident management strategy (SAMG) procedures have been developed to mitigate the consequences of such events. The primary aim of the SAMG procedures is to maintain the integrity of the fission product barriers. An important barrier is the reactor vessel and maintaining its integrity is possible only if the core material is coolable. Therefore, the SAMG procedures consider the in-vessel reflooding. Due to the porosity, which allows easier coolant intrusion, the debris bed provides greater chances for cooling than a pool of molten corium. In the case of not sufficient cooling, with the continuation of the accident scenario the melting of the degraded reactor core and its relocation to the lower reactor vessel plenum occurs. To prevent the ex-vessel melt release, the in-vessel melt retention strategy could be applied.

The debris bed coolability was recognized as an important nuclear safety issue in the frame of the EU SARNET-2 (Severe Accident Research NETwork of Excellence) programme (Pohlner et al., 2014). In the EU SARNET-2 programme the debris bed formation due to the fuel-coolant interaction and the coolability of the formed debris bed were analysed. The purpose of our research is to understand the in-vessel debris bed coolability during the bottom reflooding.

Several experiments on the debris bed coolability in the bottom reflooding conditions were performed. Tutu et al. (Tutu et al., 1984a; Tutu et al., 1984b) performed a bottom reflooding experiment with a preheated homogeneous test section containing $18 \mathrm{~kg}$ of debris. The purpose of the experiments was to validate the analytical models. In the performed experiments, quenching of superheated debris bed was observed and the advantage of the bottom reflooding over the top reflooding due to the increased heat flux was recognised. Next, Wang and Dhir (1988) performed an experiment with the bottom reflooding of $71 \mathrm{~kg}$ of debris in a homogeneous geometry, which was heated by induction. It was found that an increased pressure drop across the debris bed increases the multidimensional effects and reduces the quenching time. Further, in the DEBRIS experimental facility at IKE, Germany (Chikhi et al., 2014; Leininger et al., 2014; Schäfer et al., 
2006; Starflinger et al., 2015), bottom and top reflooding were performed. Because of the uniform debris bed, the bottom reflooding was clearly one dimensional across the whole debris bed section. In the POMECO experimental facility at KTH, Sweden (Chikhi et al., 2014; Kazachkov and Konovalikhin, 2002; Nayak et al., 2006), the bottom reflooding was simulated with the downcomers, which significantly enhance reflooding of the debris bed compared to the only top reflooding.

Under the PROGRES research program experiments are being performed at the PRELUDE and PEARL facilities at IRSN, France (Bachrata et al., 2013; Chikhi et al., 2014; Chikhi and Fichot, 2017; Fichot et al., 2012; Pohlner et al., 2014; Repetto et al., 2013). The PROGRES experimental program was launched to highlight the behaviour of a steam and water flow in a hot porous medium and to provide experimental data to validate the 2-D and 3-D models for the debris bed reflooding (IRSN Research programs, 2016). The PROGRES experimental program is used to investigate the phenomena and consequences of the water reflooding of simulated damaged reactor core, when most of it had been collapsed and had formed a debris bed. The PEARL facility is with $500 \mathrm{~kg}$ of debris devoted to the bottom and top debris bed reflooding on a large scale. In contrast to the most of the earlier experiments where the test sections were homogenous, the PEARL test section consists of different zones, allowing investigating the effect of differences in geometry. Chikhi and Fichot (2017) presented the main results of some of the PEARL reflooding experiments and developed an analytical model, which takes into account the deviation of water from central debris bed into the bypass. The effect of the bypass and twodimensional reflooding in the PEARL experiments were also analysed with numerical simulations using the ICARE-CATHARE code (Chikhi et al., 2017).

To describe the general features of the debris bed reflooding phenomena computer codes were developed, including MEWA from IKE, DECOSIM from KTH, CORIUM-2D from RSE, Italy, and PORFLO from VTT, Finland (Parozzi et al., 2010; Pohlner et al., 2014). Recently, the MC3D code from IRSN was upgraded to enable the debris bed coolability modelling (Raverdy et al., 2017). The MC3D code is devoted to the multiphase flow simulations in thermal-hydraulics and nuclear safety studies (Meignen et al., 2014). Its major use is in the fuel-coolant interaction phenomena evaluation. The applicability of the MC3D code to simulate the cooling of a debris bed was already demonstrated with some first simulations of the PEARL experiments (Raverdy et al., 2017). The analysis of performed simulations have shown an important role of the bypass at high injection velocity and high initial bed temperature on the water and steam flow path and reflooding time. Some general trends of validation of the MC3D code may also be found in Mutelle et al. (2017). Although there are various uncertainties for modelling, namely the role of interfacial frictions between water and steam, and the precise heat and mass transfer mechanisms, the results obtained are considered as sufficient, first, for explaining the general features of the flow, second, in regards of the general high uncertainties during a severe accident and debris bed formation.

The purpose of the paper is to analyse with the MC3D code the debris bed bottom reflooding experiments at atmospheric pressure performed in the PEARL facility. Our aim is to analyse the flow in the 2-D porous debris bed with bypass. Further, our aim is to perform a complementary validation of the MC3D code, to give insights into the effect of different experimental conditions on the results and to analyse the effect of potential uncertainties of the experimental conditions on the simulation results. 


\section{PEARL experiment}

In the PEARL experiments performed in frame of the PROGRES campaign $n^{\circ} 1$, the effects of initial debris bed temperature, inflow water velocity and pressure were investigated (Chikhi and Fichot, 2017). In this paper, the focus is only on the experiments performed at the atmospheric pressure.

In this section, the experimental setup and the experimental findings are briefly reminded.

\subsection{Experimental setup}

In the PEARL experiments, the test section consisted of a vertical tube with internal diameter $540 \mathrm{~mm}$ and length of $2.6 \mathrm{~m}$ (Chikhi and Fichot, 2017). As sketched in Figure 1, the debris bed with diameter of $450 \mathrm{~mm}$ and height of $500 \mathrm{~mm}$ consisted of stainless steel balls with diameter of $4 \mathrm{~mm}$. Quartz balls with diameter of $8 \mathrm{~mm}$ supported the steel debris bed. Below as well as above the debris bed was a layer of quartz balls of $100 \mathrm{~mm}$ and $50 \mathrm{~mm}$, respectively. The steel debris bed was enclosed with a $45 \mathrm{~mm}$ layer of quartz balls, simulating the less degraded core parts.

In the PEARL experiments, first, the test section was preheated with a steam flow to the saturation temperature. In the second phase, an induction technic was used to heat the steel debris bed to the desired temperature. After that, the heating was stopped and the water injection started from the bottom. When the water level reached the debris bed, the heating of the steel debris bed was started again to simulate the decay heat. The experiments stopped when the entire temperature of the debris bed was below the saturation temperature. It was noticed that, due to the heat conduction, the quartz balls in the bypass were also initially heated. The actual mean temperature of the bypass is not known with precision in the presented experiments, but the energy contained in the bypass could be estimated to be up to nearly $30 \%$ of the total energy to be extracted (neglecting the energy of the quartz tube containing the debris bed). Also, due to the first initialization of the whole bed, including lower support, at the saturation temperature, the reflooding phase occurred first with water at saturation (during cooling of the support) and the target temperature of water was obtained only after this first phase (see Appendix A). This will be important for the analysis of the experiments.

During the experiments, the temperature and the pressure were measured at different positions. The rapid change of temperature measurements was used as a criterion to determine the quenching front velocity in the debris bed and in the bypass. The steam flow rate was measured at the top of the test section. As presented in Table 1, different initial and boundary conditions were applied (Chikhi and Fichot, 2017). 


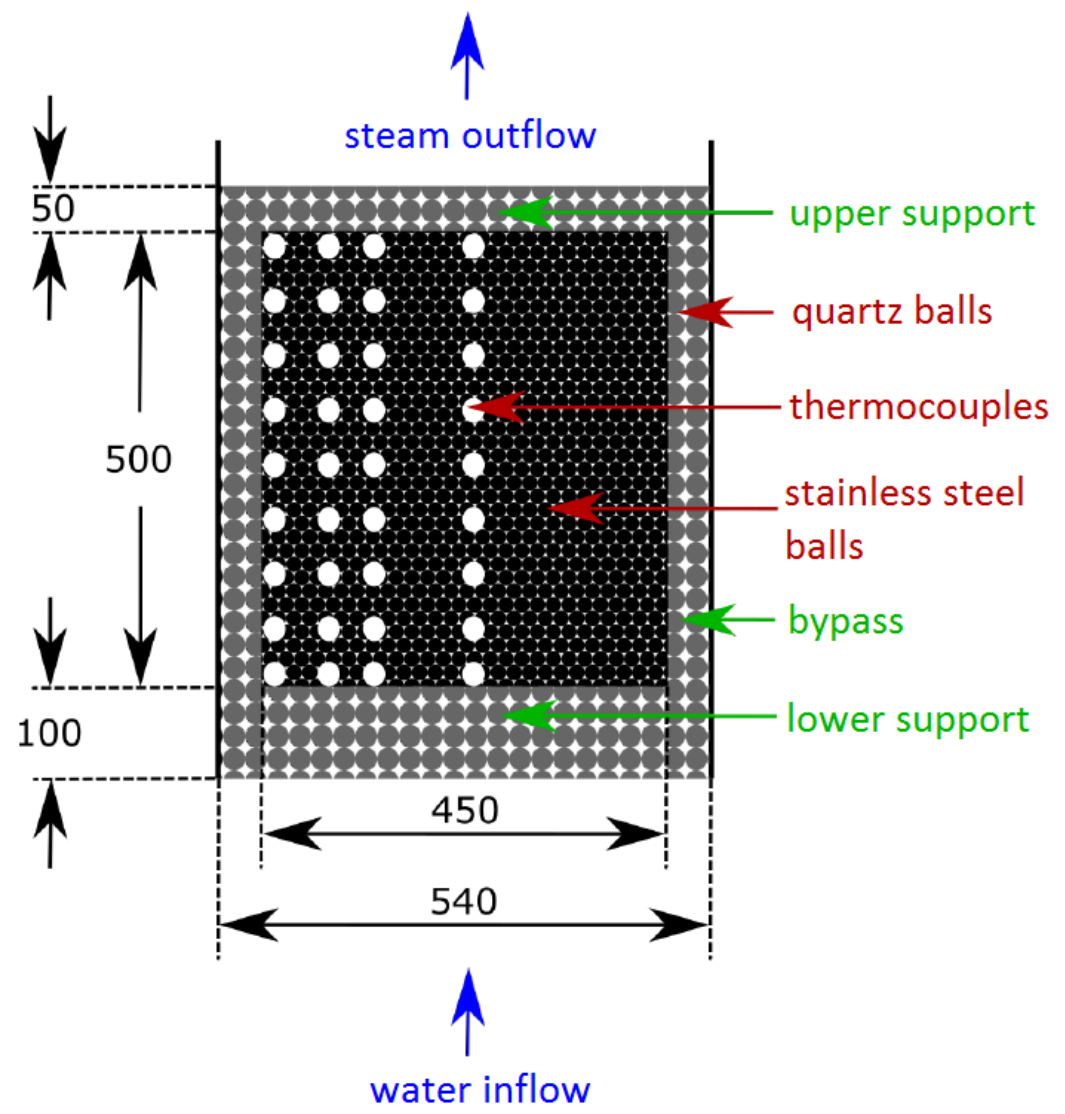

Figure 1: Schematic presentation of test section of PEARL experiment (PROGRES campaign $\mathrm{n}^{\circ} 1$ ) with measures in $\mathrm{mm}$.

Table 1: Initial and boundary conditions of selected PEARL experiments (Chikhi and Fichot, 2017). The steam production value is considered at the moment, when the debris bed was reflooded.

\begin{tabular}{|l|l|l|l|l|l|l|}
\cline { 3 - 7 } \multicolumn{2}{c|}{} & PA_0 & PA_1 & PA_2 & PA_4 & PA_5 \\
\hline \multirow{3}{*}{$\begin{array}{l}\text { initial } \\
\text { conditions }\end{array}$} & debris bed temperature [K] & 423 & 673 & 973 & 673 & 673 \\
\cline { 2 - 7 } & water velocity [m/h] & 5 & 5 & 5 & 2 & 10 \\
\cline { 2 - 7 } & induction power [W/kg] & 150 & 150 & 150 & 150 & 150 \\
\cline { 2 - 7 } & pressure [bar] & 1 & 1 & 1 & 1 & 1 \\
\hline \multirow{2}{*}{ results } & reflooding time [s] & 108 & 240 & 490 & 440 & 185 \\
\cline { 2 - 7 } & steam production [kg] & 5.4 & 28 & 58 & 30 & 27 \\
\hline
\end{tabular}

\subsection{Experimental results}

In the PA_0 (low initial bed temperature test) and PA_4 (low water injection velocity test) experimental cases, the bypass was reflooded approximately together with the steel debris bed while in the PA_1, PA_2 and PA_5 experimental cases, the bypass was reflooded faster than the steel debris bed. This shows a 1-D or 2-D type reflooding evidence depending on the initial and boundary conditions. 
For the PA_0 and PA_4 experimental cases, where mostly a 1-D reflooding behaviour was observed, two different boiling regimes phases can be distinguished (as can be seen in Figure 2). For the first phase, it can be considered, with Chikhi and Fichot (2017), that the steam flow rate was increased to around $0.08 \mathrm{~kg} / \mathrm{s}$ because of the reflooding of the hot debris bed. Following the sharp decrease of the steam flow rate, a second phase with a slowly decreasing steam flow was observed. This corresponds in fact to a residual heating maintaining the flow at saturation temperature in a nucleate boiling regime for the time necessary for the full cooling of the debris bed and the bypass. This effect is largely due to the heating of the support bed to the saturation temperature, as explained above. The residual boiling disappeared when the reflooding water was actually subcooled to the target temperature. This behaviour is also visible in the PA_1 experimental case. The cooling time was however noticeably shorter.

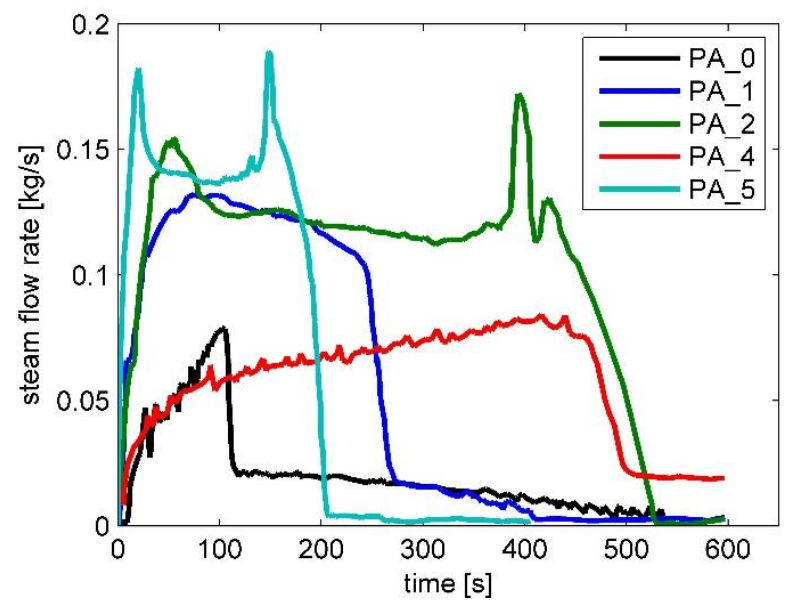

Figure 2: Experimental values for the steam flow rate for the PEARL experiments. Experimental results are extracted from (Chikhi and Fichot, 2017).

In the PA_2 and PA_5 experimental case, where a 2-D behaviour was observed, the second phase was nearly absent. This might be due to the deviation of the (saturate) water in the bypass, so that the water entering the hot debris bed was more rapidly subcooled. In contrast, rather constant steam flow rates were measured, with two maxima observed at the beginning and at the end of reflooding. The first maximum in the steam flow rate may be interpreted as the first wetting of the bottom of the debris bed and of the bypass. Only speculations could be made for the second short maximum. It might be an effect of the fast reflooding of the small layer of large quartz beads on top of the steel debris bed. Chikhi and Fichot (2017) attributed this to a possible rearrangement of the vapour flow when the hot bed is nearly flooded. However, this second peak is not considered as significant for both the general interpretation and second for nuclear safety.

Overall, the increase of initial debris bed temperature in the experiment extended the reflooding time of the debris bed nearly linearly (Chikhi and Fichot, 2017). However, faster reflooding of the bypass was observed for the experimental cases with higher initial debris bed temperature. In Chikhi and Fichot (2017) it was assumed, that a part of water was deviated towards the bypass. Chikhi and Fichot (2017) did not conclude on the actual mechanism. In the PA_2 experimental case, quench progression in the bypass was even faster as would be, if all the water would be directed into the bypass (Chikhi et al., 2017) and swelling of water may explain this phenomenon. They pointed out, that at least two major effects would be caused by the crossflow of steam and water, which would enhance water front progression in the bypass. Firstly, the interfacial drag causes small droplets of water to be mix in the steam flow. However, although 
the ICARE-CATHARE code does not contain such drag it is capable of predicting the observed deviation in refolding (Chikhi et al., 2017). Secondly, a displacement of liquid by the volume of steam entering from the bed into the bypass would cause a swelling of the liquid in the bypass. However, it is possible to explain the deviation simply from the far higher frictional pressure drop in the vapour region, which is generated at high velocity. The higher pressure loss in the hot debris bed is compensated by a higher velocity in the bypass and the gravitational pressure difference due to the different water levels (see Appendix B).

The increase of the inflow water velocity increased the steam flow rate and reduced the reflooding time. However, the reflooding time reduction was significantly higher when the inflow water velocity was increased from 2 to $5 \mathrm{~m} / \mathrm{h}$ than when it was increased from 5 to $10 \mathrm{~m} / \mathrm{h}$. It seems that with the increasing inflow water velocity the reflooding time tends to a limit value (Chikhi and Fichot, 2017). Similar observations were done for the PRELUDE experiments (Repetto et al., 2013). A possible explanation is given in Appendix B. It may be due to the fact that the gravitational pressure head in the bypass is limited to the debris bed height.

\section{Modelling}

The simulations were performed with the MC3D version 3.8 code (Meignen et al., 2014). Thus, firstly, a brief reminder of the debris bed modelling in the MC3D code is given (Raverdy et al., 2017). After that, the construction of calculation model is described. Finally, the convergence analysis was performed to define the right mesh size, where the mesh size has no influence on the simulation results anymore. This mesh size was used for the sensitivity study simulations presented in Section 4.

\subsection{MC3D debris bed modelling}

The MC3D code (Meignen et al., 2014) is a 3-D code devoted to multiphase thermalhydraulic flow studies in the nuclear safety field. Its main application is the evaluation of Fuel Coolant Interaction (FCI). It is composed of two modules describing the premixing and the explosion stages of the FCI. Since the MC3D allows the immediate coupling with other phenomena, it can be used for other topics such as the formation of the debris bed from the corium jet fragmentation, the eventual remelting phenomenon in debris beds or the cooling of corium interacting with submerged concrete. The assessment of MC3D capabilities for the debris beds coolability has been recently investigated in (Raverdy et al., 2017).

The MC3D code uses an Eulerian approach to describe the multi-phase flow. In the case of the simulation of overheated debris bed coolability, three phases - water, steam and particles, are taken into account. Each phase is described by mass, momentum and energy conservation equations completed with specific correlations for the friction, heat and mass transfer as well as for the flow configuration (Raverdy et al., 2017). The main factor associated with the debris bed coolability topics is the friction modelling, since the friction between the debris and the coolant is considered to be the driving phenomenon. The debris beds with the debris volume fraction superior to 0.4 are considered in MC3D as dense configurations. MC3D distinguishes two groups of the friction laws: correlations between the debris and the coolant and correlations between liquid and gas phases. 
The Schulenberg and Müller (Schulenberg and Müller, 1987) correlations are set as the default MC3D version 3.8 friction laws and employed as well in our simulations. Thus, the momentum equation used in performed calculations can be written as follows:

$\frac{\partial}{\partial t} \alpha_{\phi} \rho_{\phi} v_{\phi}+\nabla \cdot\left(\alpha_{\phi} \rho_{\phi} \boldsymbol{v}_{\phi} \boldsymbol{v}_{\phi}\right)+\alpha_{\phi} \nabla P_{\phi}=\alpha_{\phi} \rho_{\phi} \boldsymbol{g}-F_{w \phi}-\Gamma_{L V} \boldsymbol{v}_{\Gamma}+\frac{\left(1-\alpha_{P}\right) F_{i}\left(v_{G}-v_{L}\right)}{\left|\boldsymbol{v}_{G}-v_{L}\right|}$,

where $\alpha$ denotes the volume fraction, $\rho$ the density, $\mathrm{v}$ the velocity vector, $\mathrm{P}$ the pressure, $\mathrm{g}$ the gravity, $F_{w \phi}$ the porous wall frictions, $\Gamma_{L V}$ the mass transfer due to condensation or evaporation, $\boldsymbol{v}_{\Gamma}$ the donor phase velocity in the mass transfer, $\varepsilon$ the porosity, $F_{i}$ the interphase liquid-gas frictions, and the subscript $\phi$ designates the gas, liquid or particle (debris) phase. The porous wall frictions describe the viscous and inertial effects as follows:

$$
F_{w \phi}=\frac{\alpha_{\phi}^{2} \mu_{\phi}}{K K_{\phi}} v_{\phi}+\frac{\alpha_{\phi}^{3} \rho_{\phi}}{\eta \eta_{\phi}}\left|\boldsymbol{v}_{\phi}\right| \boldsymbol{v}_{\phi}
$$

with $\mu$ the dynamic viscosity. The Ergun model is employed in MC3D default description of the permeability $\mathrm{K}$ and the passability $\eta$ :

$$
K=\frac{\left(1-\alpha_{P}\right)^{3} d_{P}^{2}}{150 \alpha_{P}^{2}} \quad \text { and } \quad \eta=\frac{\left(1-\alpha_{p}\right)^{3} d_{P}}{1.75 \alpha_{P}},
$$

where $d_{P}$ denotes the particle diameter. The relative permeability $K_{\phi}$ and relative passability $\eta_{\phi}$ are described as follows:

$$
\begin{gathered}
K_{\phi}=\left(\frac{\alpha_{\phi}}{1-\alpha_{P}}\right)^{3} \quad \text { and } \quad \eta_{L}=\left(\frac{\alpha_{L}}{1-\alpha_{P}}\right)^{5}, \\
\eta_{G}=\left\{\begin{array}{ll}
\left(\frac{\alpha_{L}}{1-\alpha_{P}}\right)^{6} & \text { for } \alpha_{L}>\sqrt{0.1}\left(1-\alpha_{P}\right) \\
0.1\left(\frac{\alpha_{L}}{1-\alpha_{P}}\right)^{4} & \text { for } \alpha_{L}<\sqrt{0.1}\left(1-\alpha_{P}\right)
\end{array} .\right.
\end{gathered}
$$

The friction law between the liquid and the gas used in our computations is:

$$
F_{i}=350 \frac{\alpha_{L}^{7} \alpha_{G}}{\left(1-\alpha_{P}\right)^{6}} \frac{\rho_{L} K}{\eta \sigma}\left(\rho_{L}-\rho_{G}\right) \boldsymbol{g}\left(\frac{j_{G}}{\alpha_{G}}-\frac{j_{L}}{\alpha_{L}}\right)^{2}
$$

where $j_{G}$ and $j_{L}$ denotes the gas and liquid filtration velocities in porous medium.

The heat exchange models are based on the heat transfer models for a single drop. The heat transfer modelling also depends on a flow map, which is based on the relative volume fraction of gas and liquid. At low relative fraction of gas (0.1), the flow is considered as bubbly and the melt particles are either in a direct contact with water or through the vapour film. At high relative fraction of gas (0.9), the flow is considered as gas with some liquid droplets and the melt particles are in contact with the gas. In between is the transition flow. The heat transfer in convection regime is computed by the classical convection correlation. For the film boiling, the Sakurai correlation (Sakurai, 1990) is considered. In the temperature range between the saturation 
temperature and $100 \mathrm{~K}$ above the saturation temperature, a linear transition between the film boiling and convection regime is considered (Raverdy et al., 2017).

\subsection{Calculation model}

We are not aiming to evaluate and validate precisely the MC3D model, but to check at the impact of various uncertainties. So, a rather simple modelling is sufficient.

As seen in Figure 3, a simplified 2-D geometry was applied. The mesh was axial symmetrical and cylindrical coordinates were used. The radius of the domain was $0.27 \mathrm{~m}$ (radius of PEARL test section) and the height was $2 \mathrm{~m}$ to ensure that only steam is exiting the simulating domain. The test section was divided into several zones. The support bed (at saturation temperature) is reduced in height to $0.1 \mathrm{~m}$, whereas it is about $0.7 \mathrm{~m}$ in the experiment. Thus, we anticipate that some details, resulting from the cooling of this region, may not be reproduced. From height $0.1 \mathrm{~m}$ to $0.6 \mathrm{~m}$ and from radius $0 \mathrm{~m}$ to $0.225 \mathrm{~m}$ the debris bed zone was defined. In the debris bed zone the porosity was set to 0.4 and balls with diameter of $4 \mathrm{~mm}$ were used. Additionally, the volumetric power was applied in the debris bed zone. At the same height at the outside of the debris bed zone, the bypass zone was defined between radius $0.225 \mathrm{~m}$ and $0.27 \mathrm{~m}$. In the bypass zone, the porosity was set to 0.4 and balls with diameter of $8 \mathrm{~mm}$ were used. Below and $50 \mathrm{~mm}$ above the debris bed and bypass zones also the support zones with porosity set to 0.4 and balls with diameter of $8 \mathrm{~mm}$ were defined. Above the height of $0.65 \mathrm{~m}$, only steam was set.

In the simulations, the initial conditions were the same as in the experiment (see Table 1), with some corrections described below. Water with initial temperature of $343 \mathrm{~K}$ was injected through the bottom boundary of the test section and the pressure of 1 bar was set at the top boundary. It is recalled that the actual reflooding temperature is about $300 \mathrm{~K}$, but the large support bed induces a heating of water close to saturation for some time. The water temperature will be considered as a sensitivity parameter (see Section 4.3).

Two patches of the MC3D version 3.8 code were used. The majority of simulations were performed with the MC3D version enabling only one material modelling. This version was used for the sensitivity analysis presented in Sections 4.1, 4.2, 4.3 and 4.4 where the stainless steel properties were used for both the stainless steel balls in the debris bed and the quartz balls surrounding the debris bed. In this case, the temperature of the balls in the bypass, upper and lower support zones was set to the value at which the available internal energy is the same as for the quartz balls at the saturation temperature (considering the specific heat and density). The possibility to add another material was added to further MC3D version and calculations with this improvement are shown and discussed in Section 4.5. In any case, it is important to highlight that the actual mean temperature in the bypass is not known with precision. The thermocouples are set close to the wall, and the measured temperature is then not fully reliable. Some sensitivity calculations were performed where the temperature in the bypass was set to an average between the debris temperature and the saturation supposed to be representative of the wall temperature (see Section 4.2). Also, the calculations with two different materials for the debris and the bypass used the same hypothesis.

In the MC3D simulations, the quenching front propagation and the steam outflow were monitored. With reflooding, the temperature of the balls falls rapidly to few degrees above the saturation temperature. In the simulations, the debris bed was considered to be cooled when its temperature falls below $10 \mathrm{~K}$ above the saturation temperature. 


\subsection{Convergence analysis}

The convergence analysis was performed by varying the mesh density. The number of cells in radial and axial directions was varied from 2 to 46 and from 4 to 124, respectively. A progressive grid conserving the cell volume was used in the radial direction. A regular grid was used in the axial direction in the region of the bottom support, debris bed and bypass zones. Above the debris bed zone, the cells height gradually increases with increasing distance from the debris bed zone.

As seen in Figure 4, the integral mass of steam converges with increasing number of cells. However, only the coarsest mesh, where the debris bed is represented by only one cell, gives significantly different results in terms of steam production rate.

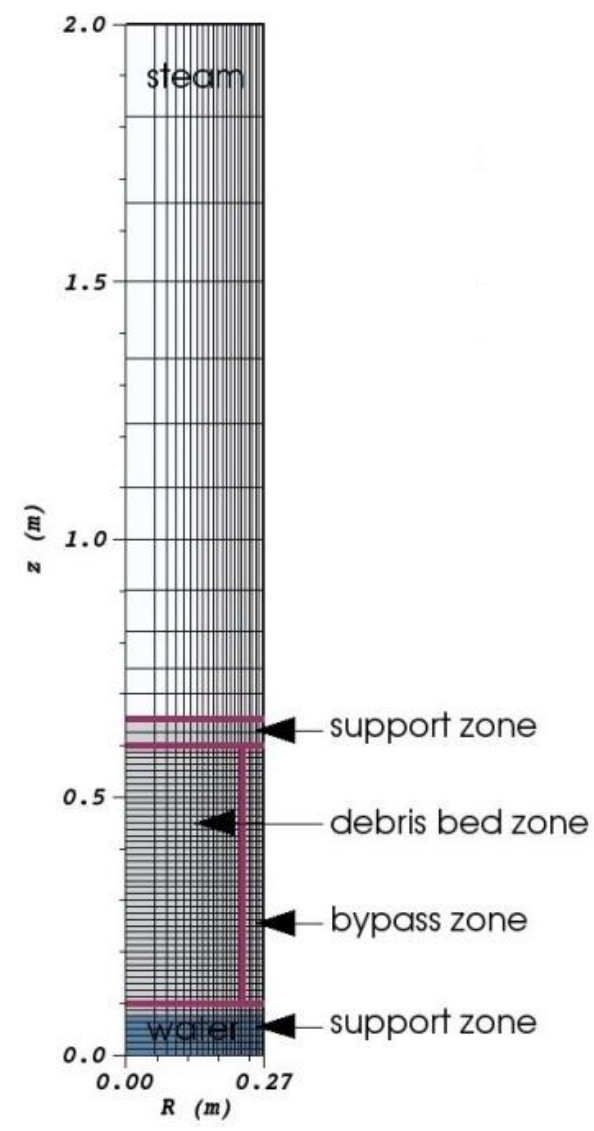

Figure 3: Computational geometry with $23 \times 62$ cells.

Based on the results of the convergence analysis, the mesh size of $23 \times 62$ cells was chosen. Using finer meshes does not give any greater differences in the results compared to the selected mesh. For the selected mesh the height of the cells in the region of the bottom support, debris bed and bypass zones was set to $1.25 \mathrm{~cm}$. In the upper support zone, the cell height was set to $2.5 \mathrm{~cm}$. Above the upper support zone the cell height was increased with the rate of $2.5 \mathrm{~cm}$ for every second cell. 


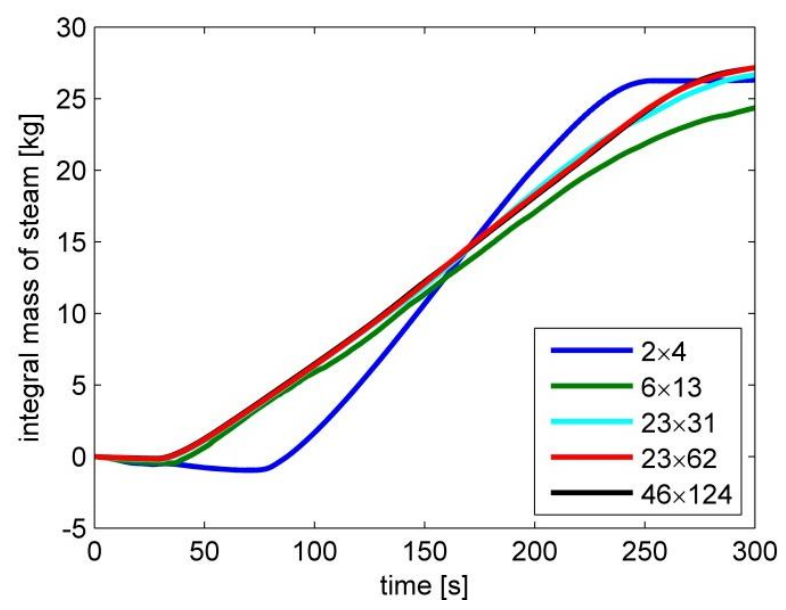

Figure 4: Integral mass of produced steam for different meshes.

\section{Sensitivity analysis}

First, the PEARL experiments were simulated, using the same conditions as given in Table 1. The simulation results are compared to the experimental one. However, some of the initial and boundary conditions are not known exactly or there might be some non-homogeneity in the test section. Therefore, to assess the effect of potential uncertainties in the experimental conditions a sensitivity analysis of those parameters was performed. In addition, the heat transfer modelling was inspected to analyse the effect of uncertainties in the modelling approaches. By the performed parametric analysis, also insight in the influence of various modelling parameters on the simulation results is obtained. Different simulation cases, performed in the sensitivity study are summarized in Table 2.

Table 2: Description of the performed simulation cases.

\begin{tabular}{|l|l|l|}
\hline simulation case & dedicated to & description \\
\hline basic & $\begin{array}{l}\text { Reference case with the inflow water temperature } \\
\text { of 343 K, bypass and support at saturation } \\
\text { temperature. }\end{array}$ \\
\hline T quartz + & initial conditions & $\begin{array}{l}\text { Support and bypass zones have an average } \\
\text { temperature between the saturation temperature } \\
\text { and the temperature of the debris bed zone. }\end{array}$ \\
\hline porosity + & initial conditions & Porosity increased for 10\% to 0.44. \\
\hline porosity - & initial conditions & Porosity lowered for 10\% to 0.36. \\
\hline T water + & boundary conditions & Inflow water temperature increased to 373 K. \\
\hline T water - & boundary conditions & Inflow water temperature decreased to 313 K. \\
\hline HT + & modelling approaches & $\begin{array}{l}\text { Heat transfer coefficient for the convective and } \\
\text { conductive heat transfer between the melt droplet } \\
\text { and its surrounding is doubled. }\end{array}$ \\
\hline HT - & modelling approaches & $\begin{array}{l}\text { Heat transfer coefficient for the convective and } \\
\text { conductive heat transfer between the melt droplet } \\
\text { and its surrounding is halved. }\end{array}$ \\
\hline
\end{tabular}


Results in Sections 4.1, 4.2, 4.3 and 4.4 shows the produced steam flow rates for all calculations with one material. In the following, we will firstly discuss the general features of the "basic" calculations, then the impact of initial conditions, the impact of the boundary conditions and those related to the heat transfer. Finally, in Section 4.5 the effect of material properties is discussed.

\subsection{Basic simulation}

The PA_0 experiment was performed with a lower temperature of the debris bed balls than the other experiments. In Figure 5, the steam flow rate for the simulation of the PA_0 experiment is shown. The steam flow rate in the "basic" simulation case is lower than in the experiment and the reflooding time is longer. Due to the longer reflooding time, also the heating time is longer, providing more energy into the system, and consequently the calculated integral mass of steam at the reflooding time is larger than in the experiment (compare Table 1 and Table 3). Nevertheless, the specific trend of gradually increasing mass flow rate, up to the complete flooding, is recovered. However, as it will be explained in Sections 4.2 and 4.3, a better adjustment is found with more realistic bypass temperature ("T quartz + " simulation case) and water temperature ("T water +" simulation case).
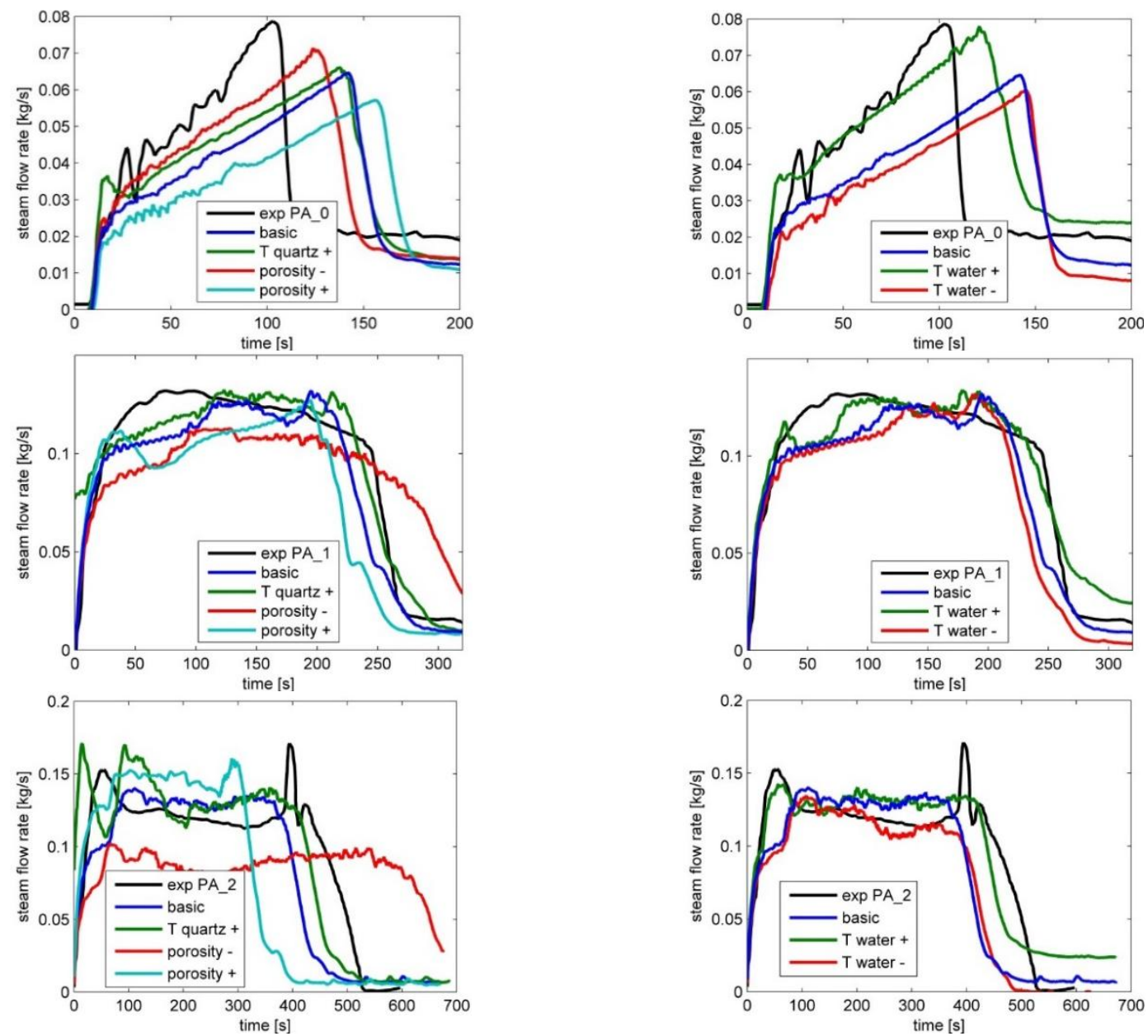

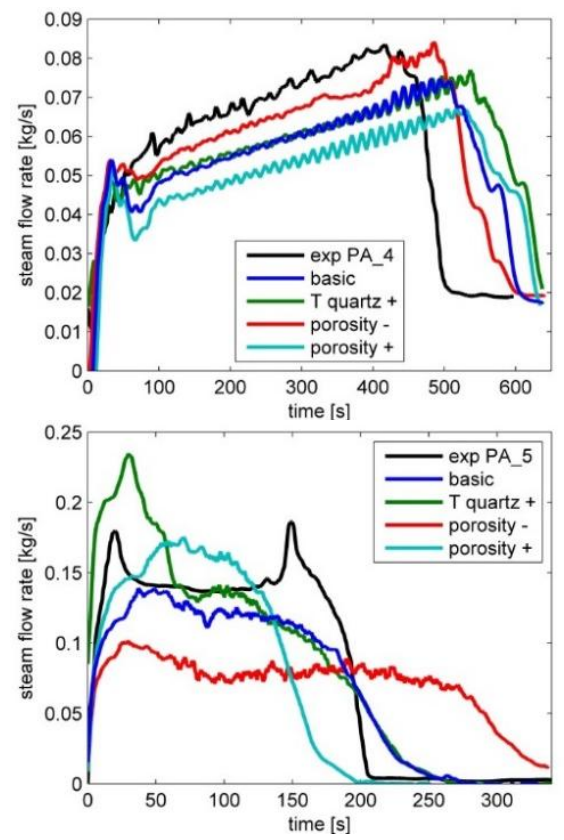
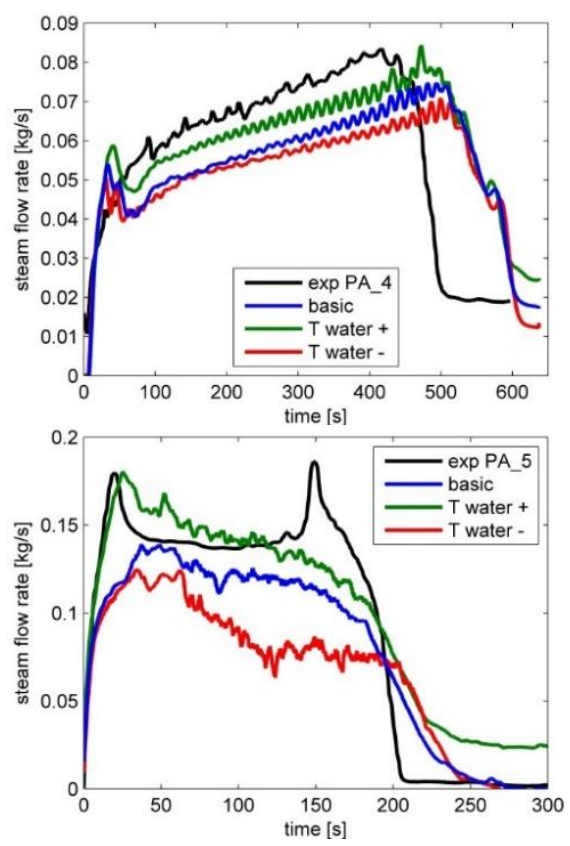

Figure 5: Comparison of the experimental results with the "basic" simulation case and the effect of initial (on the left) and boundary (on the right) conditions on steam flow rate for the PA_0, PA_1, PA_2, PA_4 and PA_5 simulation case.

Table 3: Calculated results for reflooding time and integral mass of steam for the "basic" simulation cases.

\begin{tabular}{|l|l|l|l|l|l|}
\cline { 2 - 6 } \multicolumn{1}{c|}{} & PA_0 & PA_1 & PA_2 & PA_4 & PA_5 \\
\hline reflooding time [s] & 148 & 263 & 462 & 535 & 246 \\
\hline steam production $[\mathrm{kg}]$ & 5.9 & 27 & 52 & 31 & 24 \\
\hline
\end{tabular}

The PA_1 case had the temperature of the debris bed and the inflow water velocity inbetween the boundary values of the experimental series (see Table 1). Because the other experimental cases are varied around the PA_1 case, the phenomenon of reflooding is discussed in more details for the PA_1 case. In Figure 6, snapshots of the test section reflooding are shown for the "basic" simulation case at various times. In the lower support zone, the water level rises evenly through the whole section. In the simulation, it takes $28 \mathrm{~s}$ for water to reach the debris bed (first snapshot). At that moment, as can be observed from the isotherms, the lower support zone is not completely cooled down to the inflow water temperature. After reaching the hot balls in the debris bed zone, the water starts to evaporate. At $100 \mathrm{~s}$ and later the hot steam also heats the upper support zone above $400 \mathrm{~K}$. Similar to experimental observations (see Section 2.2), the bypass is a preferential path for both water and steam (above the water level). In the beginning, no evidence of water entrainment by the steam in the bypass can be given from the calculations (although the model includes skin frictions between water and vapour) to explain the deviation of water. However, as seen in Figure 6, steam produced in the debris bed zone tends lately to flow towards the bypass zone and mix with the water. Towards the end, the bypass flow tends to onephase and (see Figure 6) the preferential path for steam is changed to directly upward. Although the water floods the bypass zone faster than the debris bed zone and some water flows through the bypass zone above the upper support zone, no reflooding of the debris bed zone from the top occurs in the simulation. These calculated phenomena are in agreement with the experimental 
findings discussed in Section 2.2. As seen in Table 3, the reflooding time in the "basic" simulation case of the PA_1 experiment matches well with the experimental one (Table 1). However, as seen in Figure 5, the simulated steam flow rate in the second half of the reflooding is similar to the experimental value but in the first half it is about $20 \%$ lower.

In the PA_2 experiment, the initial debris bed temperature was set to $973 \mathrm{~K}$, which is closer to what is expected in the case of debris bed in a reactor vessel. As seen in Table 3, the reflooding time in the "basic" simulation case is about $6 \%$ shorter than in the experiment (Table 1). The steam flow rate in the "basic" simulation case is slightly above the experimental values (Figure $5)$, but the two peaks measured in the experimental case are not reproduced. In total, about $10 \%$ less steam is produced in this simulation case than in the experiment (see Table 3 ).

The experimental cases PA_4 and PA_5 were performed with different inflow water velocity in regard to the other experimental cases (see Table 1). In the PA_4 experimental case, the inflow water velocity was set to $2 \mathrm{~m} / \mathrm{h}$, whereas in the PA_5 experimental case it was set to $10 \mathrm{~m} / \mathrm{h}$. As seen in Figure 5, the generic trends of the simulation of the PA_4 experimental case are similar to those for the PA_0 case, where the debris bed temperature is lower, similarly to the experimental results. The reflooding time in the "basic" simulation case is about $20 \%$ longer than in the experiment (see Table 1). The steam flow rate is lower than in the experimental case, but because of the longer reflooding time and consequently longer heating, the integral mass of steam is comparable to the experimental one (see Table 3 ).
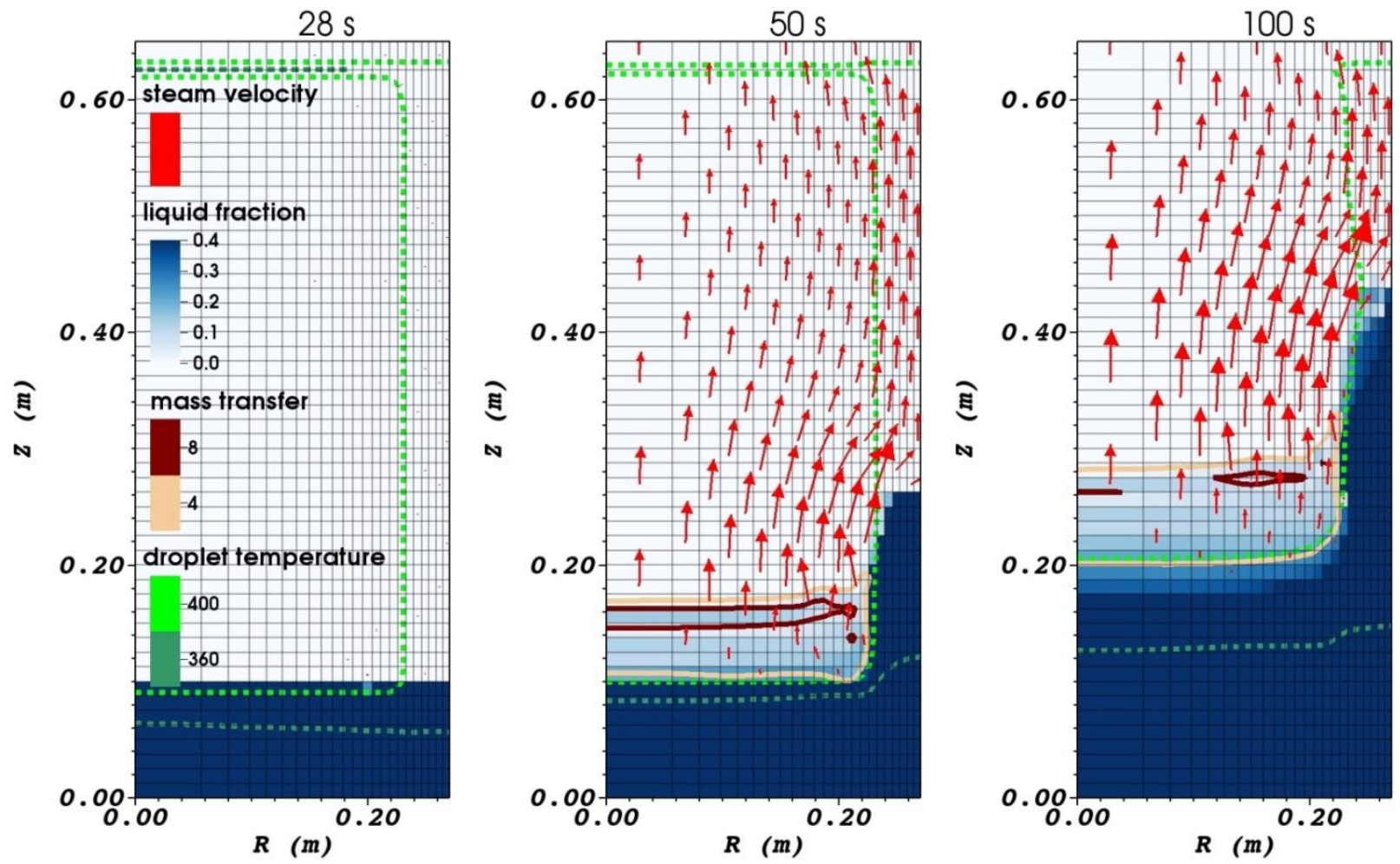

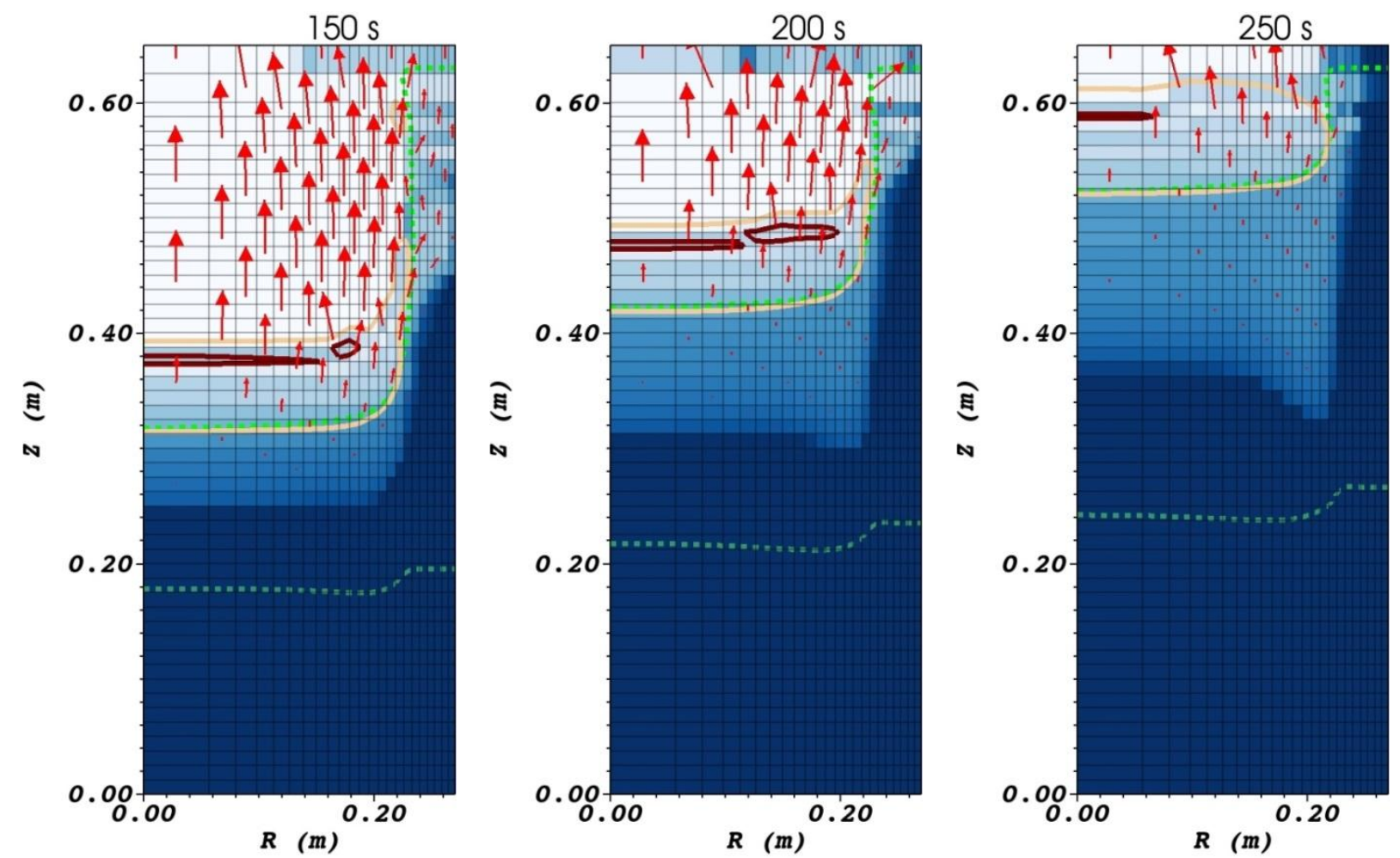

Figure 6: Snapshots of reflooding simulation at various times for the PA_1 "basic" simulation case. Steam velocity (vectors), liquid fraction (field), mass transfer between liquid water and vapour (solid curves; values in $\mathrm{kg} / \mathrm{m}^{3} \mathrm{~s}$ ) and droplet temperature (dashed curves; values in $\mathrm{K}$ ) are shown.

In the "basic" simulation case of the PA_5 case, the reflooding time is longer and the steam flow rate is lower than in the experimental case (Figure 5). The reason might be the strong thrusting of water in the bypass zone. Regarding the reflooding time and the steam flow rate in comparison to the experimental results, the simulation of the PA_5 case shows similarity to the simulations of the PA_0 and PA_4 cases.

To summarize, in general, the MC3D results are in relatively good agreement with the experiments. The simulation results for the quasi-steady reflooding period are qualitatively similar to the experiments, while the transients are more difficult to reproduce. It can be observed, that the reflooding time in the "basic" simulation cases is extended (except for the PA_2 case) while the steam flow rate and the integral mass of steam are underpredicted. Reflooding time may be related to the flow through the bypass and consequently to the modelling of the hydraulic resistance of different sections within the MC3D code. When comparing the integral mass of steam the additional heating time must be taken into account because of the longer reflooding. The 2-D versus 1-D behaviour of flooding is well captured. The water deviation to the bypass, when it occurs, is not due to entrainment by steam, but rather due to the high pressure loss in the vapour region of the debris bed (see Appendix B). 


\subsection{Sensitivity analysis of initial conditions}

Some observed discrepancy between the experimental results and the "basic" simulation cases in the previous section might be a consequence of the applied initial conditions in the simulations. Therefore a sensitivity analysis of the initial conditions was performed.

In the "T quartz +" simulation case a higher temperature of the bypass and support zones than in the "basic" case is considered. In contrast to the "basic" simulation case where the bypass and support zones temperature corresponds to the saturation temperature, in the "T quartz +" simulation case the temperature of support and bypass zones corresponds to an average temperature between the saturation temperature and the temperature of the debris bed zone (see discussion in Section 3.2). As seen in Figure 5, during the "T quartz +" simulations, the steam flow rate is higher and more steam is produced than in the "basic" simulation case. That can be explained with the higher internal energy of the bypass and support zones. Initially, the steam flow rate is not equal to zero because also in the lower support zone evaporation occurs. As seen in Figure 5, in the "T quartz +" simulation case for the PA_1, PA_2 and PA_4 cases it takes longer as in the "basic" simulation cases for water to reflood the whole debris bed zone. For the PA_4 case, the steam flow rate in the "T quartz +" simulation case does not differ notably from the "basic" simulation case except that it lasts a few tens of seconds longer. As seen in Figure 5, at the beginning of the "T quartz +" simulation case for PA_0, PA_2 and PA_5, when the hot debris bed is firstly wetted and the support and bypass zones are being reflooded, a peak in the steam flow rate can be observed. Also, when the water level reaches the debris bed zone, the lower support zone is not completely cooled down yet. The water flowing in the debris bed zone has therefore a higher temperature than at the inlet and thus less energy is needed for the water heating and evaporation. In the "T quartz +" simulation case for the PA_2 case, two peaks in the steam flow rate are present at the beginning (Figure 5). The first peak might have appeared because of the fast reflooding of the bottom support zone and the bypass zone while reflooding of the upper support zone is delayed and corresponds to the second peak. As seen in Figure 5, the differences in the steam flow rate between the simulations cases are the largest for the PA_5 experimental case. The experimental data show two maximums in the steam flow rate. The first one is overpredicted in the "T quartz +" simulation case, but the second one is not reproduced.

For the PA_1, PA_2 and PA_5 "T quartz +" simulation cases, the bypass is cooled down even before it is completely reflooded. In those cases, water in the bypass swells, as it is being mixed with steam directly produced in the bypass, see Figure 7 . In contrast with what was observed from the previous simulation, with a colder bypass, the late two-phase flow in the bypass is here due to direct boiling and entrainment of vapour. It is seen that, as long as the water deviation in the bypass takes place, the steam flows in the debris bed and in the bypass are almost parallel. However, even with water swelling, reflooding of the bypass in our simulations is still a bit slower than in the experiment, as can be seen in Figure 8. Similar was observed also for to the ICARE-CATHARE calculations (Chikhi et al., 2017). Consequently, central debris bed in our simulations is cooled a bit more effectively than in the experiment. This might indicate that the friction modelling between water, steam and drops in the MC3D code should be studied further. 

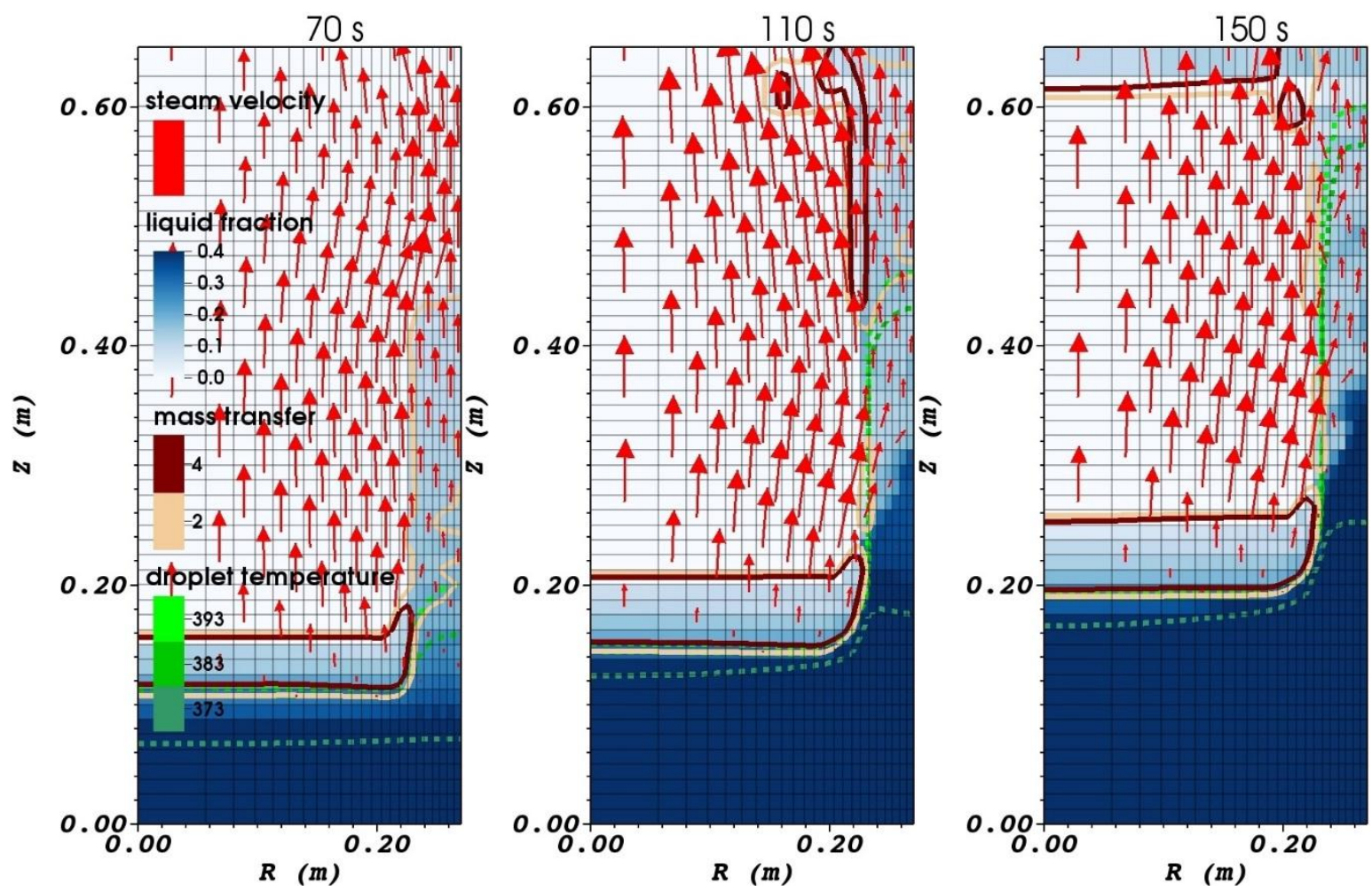

Figure 7: Snapshots of reflooding simulation at various times for the PA_2 "T quartz +" simulation case. Steam velocity (vectors), liquid fraction (field), mass transfer between liquid water and vapour (solid curves; values in $\mathrm{kg} / \mathrm{m}^{3} \mathrm{~s}$ ) and droplet temperature (dashed curves; values in $\mathrm{K}$ ) are shown.

Phenomenon of mixing water and steam in the bypass is observed in larger extend only in the "T quartz +" and "T water +" simulation cases. This mixture cools down the balls in the bypass. According to the simulation results, the relative water volume fraction of the mixture in this not completely reflooded part of the bypass is quite constant at around 0.25 . Because of this quite high volume fraction of water and large differences in the water and steam velocities, interfacial dragging of water droplets with steam is not likely mechanism for generating the water-steam mixture and the bypass reflooding in the simulations. It seems that the steam production in the bypass itself and in the support zones at the beginning of the simulation produce such amount of void that enhance swelling of water and progression of water-steam mixture in the bypass. Later on, when the bypass is almost cooled down and not much vaporization occur in the bypass, the steam flow from the central debris bed also enhance swelling. Second phase, when the steam flow form the central debris bed cause swelling of water in the bypass, is to some extend observed also in other simulation cases, but the overall effect is much smaller. Therefore, it seems that the swelling of water because of the steam flow from the central debris bed is not an important mechanism. 


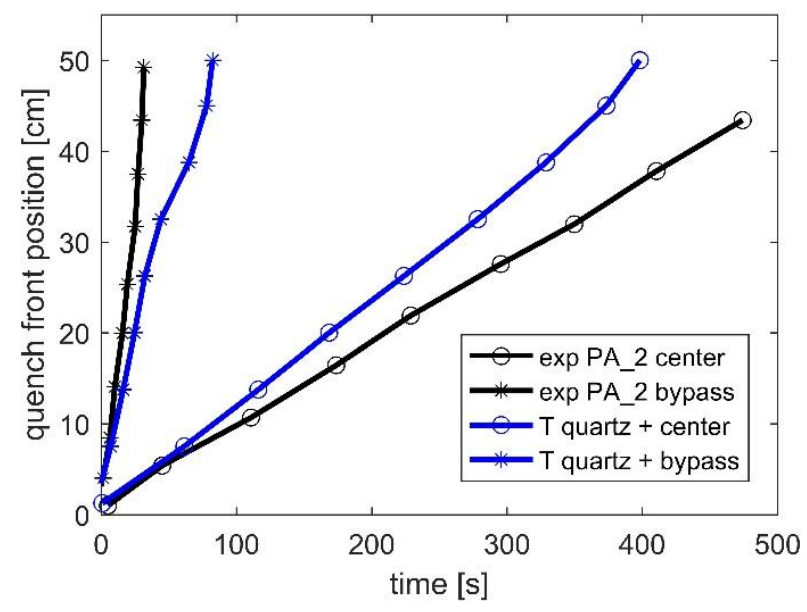

Figure 8: Quench front progression in the center of the debris bed and in the bypass for the PA_2 experimental and simulation case results.

With the "porosity +" and "porosity -" simulation cases the porosity of the debris bed, bypass and support zones is increased and lowered for $10 \%$ to 0.44 and 0.36 , respectively. The impact of the porosity depends on the conditions. As seen in Figure 5, the simulations of the PA_0 and PA_4 cases with lower debris bed temperature and low water inflow velocity show similarities. For both cases, thrusting of water in the bypass is almost negligible and the reflooding is almost 1-D. For these cases, the impact is rather small, because frictions may have a minor role (the flow rate is imposed). In the "porosity -" simulation case the balls in the test section present a higher volume fraction and consequently the whole section has a higher internal energy. Therefore, more steam is produced. The reflooding time is shorter and the steam flow rate is higher than in the "basic" simulation case. Due to the less available volume, water fills the test section faster and no additional thrusting of water in the bypass zone is observed compared to the "basic" simulation case. In the "porosity +" simulation cases more volume is available for water to fill but because of the lower total energy of the system, less water evaporates and the reflooding time is consequently only slightly extended while the steam flow rate is lower. On the other hand, as seen in Figure 5, the reflooding regime for the PA_2, PA_5 and to some extend for the PA_1 case shows different features as the regime for the PA_0 and PA_4 case. The impact of porosity is much more important in these tests with a 2-D behaviour and fast bypass flooding. This is due to the importance of frictions in the process of the bypass reflooding and the reflooding time is no more imposed by the inlet flow rate. In the "porosity -" simulation cases for PA_1, PA_2 and PA_5, thrusting of water in the bypass is more prominent. The flow of water through the bypass increases the amount of water avoiding the debris bed zone and consequently it takes longer for the debris bed to be reflooded. The slower reflooding is also a reason for lower steam flow rate compared to the "basic" simulation case. In the PA_2 and PA_5 "porosity -" simulation cases the development of the steam flow rate is like in the "basic" simulation case but stretched over a longer period and proportionally lower. In the "porosity + " simulation case, the thrusting of water in the bypass zone is weaker and consequently the reflooding is faster, even though the available volume is larger, and the steam flow rate is higher. The integral mass of steam is lower than in the "basic" simulation case, in accordance with the amount of internal energy, considering the volume fraction of the stainless steel balls.

Compared to the "basic" simulation case the integral mass of steam for the "T quartz +" and "porosity -" simulation cases matches better with the experimental value. Because of the 
changed hydraulic resistance in the case of the changed porosity, the reflooding in some simulation cases is significantly different compared to the "basic" simulation case and the experimental measurements. Thus, it seems less likely that the higher integral mass of steam in the experiment is due to smaller porosity in the test section, at least in such extend as simulated.

\subsection{Sensitivity analysis of boundary conditions}

Besides the initial conditions, also the effect of the boundary conditions on the results was investigated (see Figure 5). Inflow water temperature in the debris bed is not well characterized. For that reason, the value of $343 \mathrm{~K}$ was used for the "basic" simulation case. The actual inflow water temperature as modelled in our case may vary. At the beginning, it might be warmer and over the entire experiment, the temperature may change, compared to the constant value for the simulations. Indeed, lower water temperature $(\sim 300 \mathrm{~K})$ might be considered based on the experimental data when observing the drops temperature towards the end of the experiment (Chikhi and Fichot, 2017). Thus, in the performed sensitivity analysis of the boundary conditions, the inflow water temperature was varied for $30 \mathrm{~K}$ (besides $343 \mathrm{~K}$ in the "basic" simulation case, also $313 \mathrm{~K}$ and $373 \mathrm{~K}$ ).

As seen in Figure 5, in the "T water + " simulation cases the steam flow rate through the whole simulation is larger than in the "basic" simulation cases and the total mass of the produced steam is larger, which is expected. The higher temperature of water means that no heating of water occurs and that the energy of the balls goes directly into the evaporation. For the PA_1, PA_2 and PA_5 simulation cases with high debris bed temperature or high inflow water velocity, the increased inflow water temperature delays the reflooding time regarding to the "basic" simulation case. The time extended reflooding occurs because of the increased evaporation of water. In those cases, at the beginning of the reflooding, a maximum in the steam flow rate appears. The reason might be in water being already at the saturation conditions when reaching the hot balls. In contrast to PA_1 and PA_5, for PA_2 the maximum in the simulation agrees with the experiment. As seen in Figure 5, in the PA_4 simulation cases the maximum in the steam flow rate appears in all simulations and compared to the "basic" simulation case, the "T water +" simulation case steam flow rate is only quantitatively a bit higher. In the PA_0 "T water +" simulation case the reflooding time is shorter and the steam flow rate is increased the most.

The initial inflow water temperature in the "T water -" simulation case is $60 \mathrm{~K}$ below the saturation temperature. The reflooding time in these simulation cases is approximately the same as in the "basic" simulation cases, while the steam flow rate is slightly reduced due to the lower internal energy of water. In the second half of the "T water -" simulation cases for PA_2 and PA_5 (highest debris bed temperature and highest inflow water velocity) the steam flow rate is noticeably lower than in the "basic" simulation case.

The simulation results indicate the possibility, that at the beginning of the experiment the temperature of the water, entering the debris bed, is higher - more similar to "T water + ". The water could be heated up when flowing through the hot lower structures. After some time those lower structures are cooled down and consequently the temperature of the water coming to the debris bed is lower, i.e. similar to the "basic" simulation case. Compared to the "basic" simulation case the integral mass of steam for the "T water + " simulation cases matches better with the experimental value. 


\subsection{Sensitivity analysis of modelling approaches}

In the MC3D code, the physical models for the heat transfer for a single droplet are used. But in the porous media the heat transfer should be different. Therefore, the heat transfer coefficient for the convective and conductive heat transfer between the melt droplet and its surrounding is halved and doubled (see Table 2).

The simulations were performed for all experimental cases. The results do not show greater dependency on the heat transfer coefficient and very similar phenomena are observed for all cases. This is in agreement with Raverdy et al. (2017), where they found that the precise assessment of the heat transfer laws is not really feasible due to the low sensitivity of the results on the heat transfer modelling.

As an example, the results for the PA_1 simulation cases are presented in Figure 9, which show the largest differences but are representative also for all other cases. The main differences in the steam flow rate are observed at the beginning and at the end of the reflooding period, hereafter called transient period. In this transient period, the steam flow rate transients are slower for the "HT -" simulation case. On the opposite, the "HT +" simulation case shows faster transients of the steam flow rate. The maximum in the steam flow rate at the end of the reflooding period is higher in the "HT +" simulation case than in the "basic" simulation case while in the "HT -" simulation case it is smoothed.

Besides the changes in the heat transfer coefficient, the extension of the transient flow regime region in the flow map and the temperature profile inside the balls were considered. The changes in the flow map affect the heat transfer according to the volume fraction of the water and steam. Due to the heat transfer inside the balls, the temperature inside the balls is not constant and a temperature profile develops (Uršič et al., 2015). It turned out that these changes have only minor effect on the results and are therefore not presented and discussed herein.

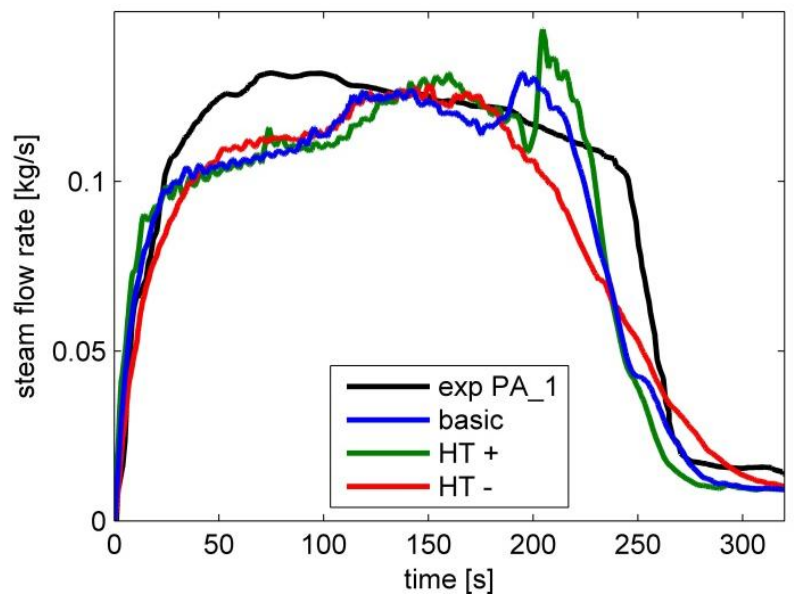

Figure 9: Effect of modelling approaches on steam flow rate for the PA_1 case.

\subsection{Sensitivity analysis of material properties}

As it was shown in Section 4.2, the estimation of an exact initial temperature of the bypass, bottom and top quartz layers seems to be one of the key parameters for better simulating the bypass cooling as well as the total steam production. The role of the bypass becomes important at high water injection velocity or high initial debris bed temperature, such as at the PA_2 case, 
where the 2-D type reflooding is observed. In the already discussed simulation cases, some simplified assumptions are considered such as the uniform distribution of the initial temperatures of debris, whereas in the PEARL experiments the axial as well as the radial differences can be observed (Chikhi et al., 2017). Moreover, another simplification of using only one material for the balls in the debris bed and bypass in the simulations is reflected by setting the initial temperature of the balls in the bypass according to the available internal energy.

Thus, additional investigation of material properties was performed and is presented hereafter. As discussed in Section 3.2, these simulations were performed with the newer version of MC3D having the possibility to add another material and thus enabling to use the actual temperatures of the balls. Similar calculation model as presented in Section 3.2 was used.

As seen in Figure 10, the MC3D predictions of the steam production for the PA_2 experiment show that two materials approach does not change the behaviour. It should be noted, that the modification enabling the use of two materials was done for an easier setting of the initial conditions.

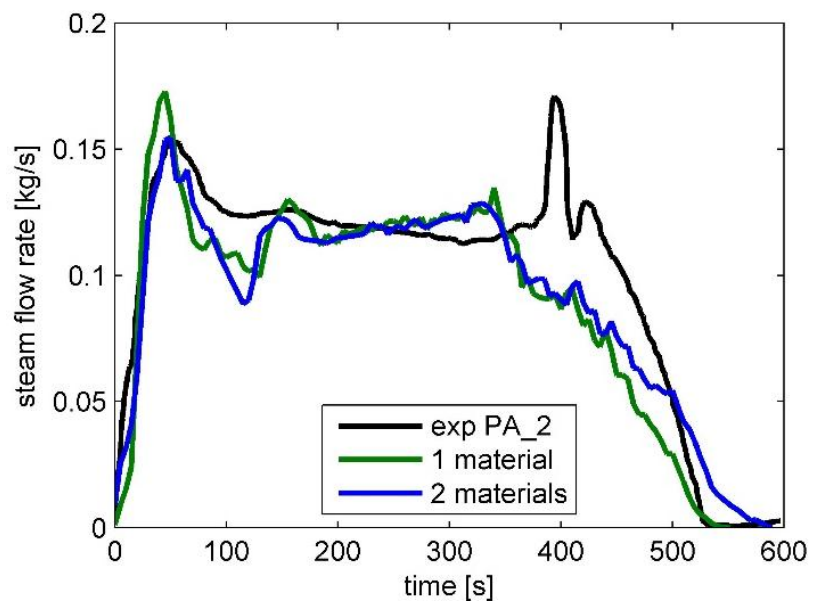

Figure 10: Comparison of one material (only steel) and two materials (steel and quartz) simulation predictions of the steam flow rate for the PA_2 case.

\section{Conclusions}

The PROGRES campaign $n^{\circ} 1$ experiments performed at the PEARL facility at atmospheric pressure were simulated with the MC3D code. The simulation results were compared to the experimental measurements. Despite various approximations in the initial and boundary conditions, in general, the MC3D code was capable to represent the experimental dynamics in good agreement with the experiments. However, simulations did not always reproduce the experimental transients. 2-D flow phenomena, such as the water entrainment in the bypass are reproduced in the simulations and the analysis of simulations gives further information on the mechanisms. In particular, water deviation into the bypass can be explained by higher frictional pressure drop in the hot debris bed.

Additionally, a sensitivity analysis was performed to assess the influence of initial and boundary conditions on simulation results and also to better describe the transient phenomena. The simulation results show some dependency on the initial and boundary conditions and 
therefore precisely knowing them is important. However, they do not impact the key trends of the flow. A key to perform simulations in good agreement with the experimental results is to detect all heat sources at the beginning of the experiment. It seems that the simulation cases with higher internal energy of the test section are in better agreement with the experimental results. In general, the reflooding times are typically longer (up to 40\%) in the simulations than in the experiments, the reason of which might be related to the chosen friction laws. However, the reflooding time is also strongly dependent on the inflow water temperature. From the simulation results it should be noted, that already minor changes in the geometry of the debris bed could have a significant effect on the reflooding of the damaged reactor core. That could greatly influence the phenomena in the scenario of severe accident mitigation in the nuclear power plant. In cases with higher internal energy, also water swelling in the bypass was observed, which might enhance cooling of the bypass debris even before they are completely reflooded with water.

In comparison to the analysis of the initial and boundary conditions, the changes in the heat transfer modelling have only a minor effect. The most visible effect is the pace of transients. Additionally, the introduction of the possibility to define different material properties simplifies the experiment simulation and gives possibility to improve the simulation results.

\section{Acknowledgments}

The authors acknowledge the financial support from the Slovenian Research Agency (research core funding No. P2-0026 and project No. PR-07608). The PROGRES program and MC3D are partly supported by EDF France.

\section{References}

Bachrata, A., Fichot, F., Repetto, G., Quintard, M., Fleurot, J., 2013. Quench front progression in a superheated porous medium: experimental analysis and model development. Journal of Energy and Power Engineering 7, 514.

Chikhi, N., Coindreau, O., Li, L.X., Ma, W.M., Taivassalo, V., Takasuo, E., Leininger, S., Kulenovic, R., Laurien, E., 2014. Evaluation of an effective diameter to study quenching and dry-out of complex debris bed. Annals of Nuclear Energy 74, 24-41.

Chikhi, N., Fichot, F., 2017. Experimental and theoretical study of large scale debris bed reflood in the PEARL facility. Nucl Eng Des 312, 48-58.

Chikhi, N., Fichot, F., Swaidan, A., 2017. Effect of water entrainment on the coolability of a debris bed surrounded by a by-pass: Integral reflood experiments and modelling. Annals of Nuclear Energy 110, 418-437.

Fichot, F., Bachrata, A., Repetto, G., Fleurot, J., Quintard, M., 2012. Quenching of a highly superheated porous medium by injection of water, Journal of Physics: Conference Series. IOP Publishing, p. 012144. IRSN Research programs, PROGRES program, http://www.irsn.fr/EN/Research/Researchorganisation/Research-programmes/pearl/Pages/Pearl-programme.aspx, 2.8.2016

Kazachkov, I., Konovalikhin, M., 2002. Steam flow through the volumetrically heated particle bed. International Journal of Thermal Sciences 41, 1077-1087. Leininger, S., Kulenovic, R., Rahman, S., Repetto, G., Laurien, E., 2014. Experimental investigation on reflooding of debris beds. Annals of Nuclear Energy 74, 42-49.

Magallon, D., 2006. Characteristics of corium debris bed generated in large-scale fuel-coolant interaction experiments. Nucl Eng Des 236, 1998-2009. 
Meignen, R., Picchi, S., Lamome, J., Raverdy, B., Escobar, S.C., Nicaise, G., 2014. The challenge of modeling fuel-coolant interaction: Part I - Premixing. Nucl Eng Des 280, 511-527.

Mutelle, H., Fichot, F., Piar, L., Repetto, G., 2017. Reflooding of large scale debris bed with bypass: effect of pressure and water flow rate, 17th International Topical Meeting on Nuclear Reactor Thermal Hydraulics (NURETH-17), Xi'an, Shaanxi, China. Nayak, A.K., Sehgal, B.R., Stepanyan, A.V., 2006. An experimental study on quenching of a radially stratified heated porous bed. Nucl Eng Des 236, 2189-2198.

Nazari, M., Vahid, D.J., Saray, R.K., Mahmoudi, Y., 2017. Experimental investigation of heat transfer and second law analysis in a pebble bed channel with internal heat generation. International Journal of Heat and Mass Transfer 114, 688-702.

Parozzi, F., Polidoro, F., Naviglio, A., Zardo, G., 2010. Fast running models of molten corium coolability for safety analysis of nuclear reactors, Congresso Nazionale ATI, Domus de Maria, Italy, p. 17.

Pohlner, G., Buck, M., Meignen, R., Kudinov, P., Ma, W., Polidoro, F., Takasuo, E., 2014. Analyses on exvessel debris formation and coolability in SARNET frame. Annals of Nuclear Energy 74, 50-57.

Raverdy, B., Meignen, R., Piar, L., Picchi, S., Janin, T., 2017. Capabilities of MC3D to investigate the coolability of corium debris beds. Nucl Eng Des 319, 48-60.

Repetto, G., Garcin, T., Eymery, S., Fichot, F., 2013. Experimental program on debris reflooding (PEARL) Results on PRELUDE facility. Nucl Eng Des 264, 176-186.

Sakurai, A., 1990. Film boiling heat transfer, Proc. of 9th Int. Heat Transfer Conf., Jerusalem, Israel, pp. 157-187.

Schäfer, P., Groll, M., Kulenovic, R., 2006. Basic investigations on debris cooling. Nucl Eng Des 236, 21042116.

Schulenberg, T., Müller, U., 1987. An improved model for two-phase flow through beds of coarse particles. International Journal of Multiphase Flow 13, 87-97.

Starflinger, J., Buck, M., Hartmann, A., Kulenovic, R., Leininger, S., Rahman, S., Rashid, M., 2015. Recent numerical simulations and experiments on coolability of debris beds during severe accidents of light water reactors. Nucl Eng Des 294, 153-160.

Tutu, N., Ginsberg, T., Klein, J., Klages, J., Schwarz, C., 1984a. Debris bed quenching under bottom flood conditions (in-vessel degraded core cooling phenomenology). Brookhaven National Lab., Upton, USA. Tutu, N., Ginsberg, T., Klein, J., Schwarz, C., Klages, J., 1984b. Transient quenching of superheated debris beds during bottom reflood. Brookhaven National Lab., Upton, USA.

Uršič, M., Leskovar, M., Meignen, R., 2015. Eulerian modelling of melt solidification impact during fuelcoolant interaction. Annals of Nuclear Energy 78, 130-139.

Wang, C., Dhir, V., 1988. An experimental investigation of multidimensional quenching of a simulated core debris bed. Nucl Eng Des 110, 61-72.

\section{Appendix A: On the second reflooding phase in some cases}

To understand the presence of the second phase of reflooding, it is firstly necessary to check at the characteristic times of cooling by conduction and by convection in water. For the later, we consider a velocity of $12.5 \mathrm{~m} / \mathrm{h}$, corresponding to the interstitial velocity for the first 3 cases PA_0 to PA_2, and a standard correlation since there is no real consensus on the most adequate correlation for convection in such debris bed (Nazari et al., 2017): 


$$
\begin{gathered}
\tau_{c o n v}=\frac{\mathrm{d}_{P}^{2}\left(\rho \mathrm{c}_{\mathrm{p}}\right)}{6 k_{L} N u}, \\
N u \approx 0.5 \operatorname{Re}^{0.6} \operatorname{Pr}^{\frac{1}{3}},
\end{gathered}
$$

where $\tau_{\text {conv }}$ stands for characteristic convection time, $c_{p}$ specific heat capacity at constant pressure, $\mathrm{k}_{\mathrm{L}}$ thermal conductivity of water and $\mathrm{Nu}$, Re and Pr the Nusselt, Reynolds and Prandtl number, respectively. For conduction, we employ the following approximation:

$$
\tau_{\text {cond }}=\frac{\mathrm{d}_{P}^{2}\left(\rho \mathrm{c}_{\mathrm{p}}\right)}{k}
$$

The Table 4 gives, along with the physical properties, the characteristic conduction and convection times for the 3 types of beads in the experiments. It is seen that the glass beads have a rather long characteristic conduction time. All other characteristic times are sufficiently small to be neglected. For the cases with small flow rate or small temperatures, the glass beads heated initially at saturation temperature give an important inertia to the cooling. In contrast, when the flow rate is high and with a high temperature of the steel debris bed, the preferential path offered by the bypass leads to the reflooding on top of the debris bed, which may contribute to condensation of the vapour produced by this residual power.

A generic diagram of the flow may then be represented as in Figure 11. Two processes are coming into play: the more or less pronounced 2-D effect (preferential flow in the bypass) and the presence of a saturated layer of water, before the subcooled water. In the calculations performed here, the thick glass layer below the bottom support plate is not accounted for as it is not expected to have a very important effect. In contrast, we concentrate our efforts on the 1-D versus 2-D effect that is the major objective of these PEARL experiments.

Table 4: Material physical characteristics and characteristic time for heat conduction and convection.

\begin{tabular}{|l|l|l|l|l|l|l|}
\hline material & $\mathrm{d}[\mathrm{mm}]$ & $\rho[\mathrm{kg} / \mathrm{m} 3]$ & $\mathrm{c}_{\mathrm{p}}[\mathrm{J} / \mathrm{kg} \cdot \mathrm{K}]$ & $\mathrm{k}[\mathrm{W} / \mathrm{m} \cdot \mathrm{K}]$ & $\tau_{\text {cond }}[\mathrm{s}]$ & $\tau_{\text {conv }}[\mathrm{s}]$ \\
\hline quartz & 8 & 2650 & 790 & 10 & 13.4 & 4.1 \\
\hline steel & 4 & 7800 & 470 & 26 & 2.3 & 2.7 \\
\hline glass & 6 & 2500 & 720 & 1.2 & 54.0 & 2.3 \\
\hline
\end{tabular}




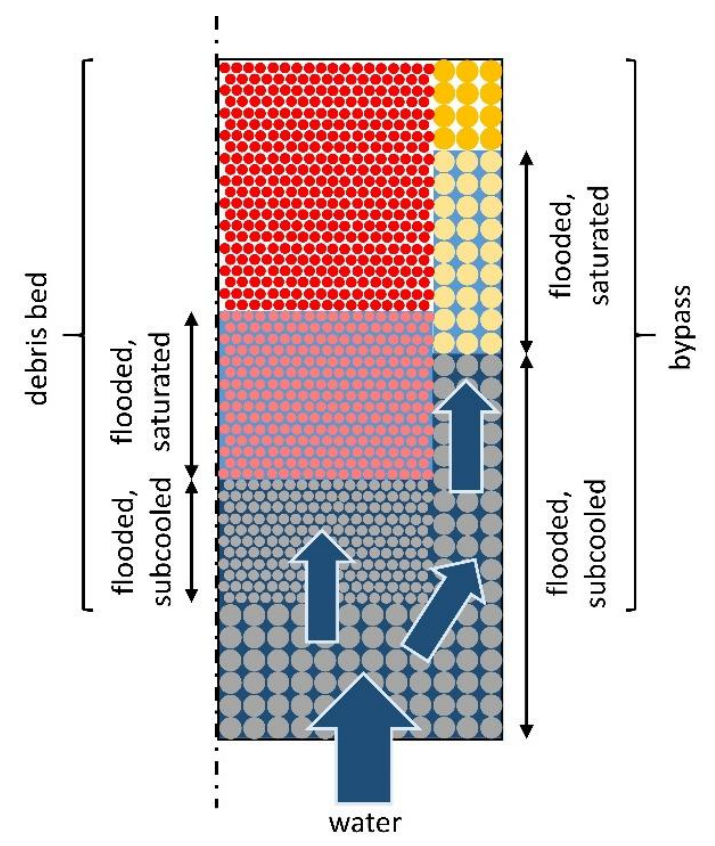

Figure 11: Generic features of the reflooding in the PEARL configuration.

\section{Appendix B: Interpretation of the 2-D behaviour and deviation of water into the bypass}

The generic behaviour of the PEARL experiments can be explained with the simplification that the flow is almost 1-D and separated in the hot debris bed and the bypass. The vapour flow in the hot debris bed can be estimated from the mass balance:

$$
\rho_{G} \boldsymbol{v}_{G P}=X \rho_{L} \boldsymbol{v}_{L P}
$$

where $\mathrm{X}$ is the fraction of water transformed into vapour, the rest of water is being used to fill the pores. Subscripts G, L and P stand for vapour, liquid water and solid particles, respectively. X has not been determined precisely (the experimental values are relative to the total flow of water) but may be in the order of 0.5. In these conditions, it is easy to show that for the pressure drop $(\mathrm{dP} / \mathrm{dz})$ the inertial term is dominant:

$$
\frac{\mathrm{d} P}{d z} \approx \frac{\rho_{L}}{\eta_{P}} v_{L P}^{2} \frac{X^{2} \rho_{L}}{\rho_{G}} .
$$

It is easy to verify that this pressure loss can be much larger than the pressure loss due to frictions in the bypass, depending on the ambient conditions (temperature, velocity, pressure...) and is compensated by the gravitational head due to the variation of water level.

In this limit, as the water level difference is limited by the height of the debris bed, we have: 


$$
\frac{\delta P}{\delta Z} \approx \frac{\rho_{L}}{\eta_{P}} \boldsymbol{v}_{L P}^{2} \frac{X^{2} \rho_{L}}{\rho_{G}} \approx \rho_{L} \boldsymbol{g} .
$$

This means that water velocity reaches a constant value independently of the flow rate, as observed in the experiments. With a value $\mathrm{X}=0.5$, we get a velocity such that the reflooding time, for the $673 \mathrm{~K}$ cases, would be of the order of $300 \mathrm{~s}$, to be compared to the value of $200 \mathrm{~s}$ found experimentally. 